\title{
Epiphany
}

Epiphany: Vol. 4, No. 1, 2011

ISSN 1840-3719

\section{Approaches to Feminist Therapy: A Case Study Illustration}

Selvira Draganović*

\begin{abstract}
This paper deals with the emergence and development of feminism in general and feminist psychology with special emphasis on feminist's reaction to traditional assumptions in Freudian psychology and male dominated theory and research. Feminist movement simply started as a women's activism which later claimed political identity and finally ended as women's liberation movement. Feminists simply advocate gender equality. Emergence of feminist psychology movement and appearance of significant female figures in psychology is further explained along with their contribution to the theory, personality and specific developmental issues along with its input to the therapy and counseling field. The influence of four feminist philosophical approaches namely, liberal feminism, cultural feminism, radical feminism and social feminism are also shortly discussed alongside with their practical implications. Above and beyond, feminist contribution to the therapy field reflected in offering specific therapy goals are also discussed. Self esteem as a core issue and one of feminist therapy goals is finally discussed and presented through a specific case study illustration. Feminist therapy is important therapy approach with significant therapy goals contribution in relation to women's mental health issues. Consideration of sex, gender, cultural diversity, etiology, diagnosis and treatment is feminist request for successful therapy because fixing woman for functioning in a dysfunctional society seems not enough.
\end{abstract}

Key words: feminism, feminist psychology, feminist theory, feminist therapy and counseling, feminist philosophical approaches

\footnotetext{
* Corresponding author: Selevira Draganović; Faculty of Arts and Social Sciences, International University of Sarajevo, Sarajevo, Bosnia and Herzegovina; e-mail: sdraganovic@ius.edu.ba; selvirad@hotmail.com
} 


\section{Introduction}

The term feminism has been provoking disparate feelings and thoughts to the effect that it is being viewed as both, positive and negative. However, there is nothing wrong with the notion that all human beings possess the right to pursue their liberties regardless of gender, race, religion etc. Therefore, the core of feminist theory as the belief in gender equality complies with liberal values and human rights. This is affirmed by the feminist definition of Funkerburk and Fukuyama (2001) who held "belief that human beings are of equal worth and that the pervading patriarchal social structures which perpetuate hierarchy of dominance, based upon gender, must be resisted and transformed toward a more equitable system" (pg.4).

Thus, this article represents a small endeavor to outline feminism, feminist psychology and feminist therapy significance and contribution. How did feminism in general emerge and why, what is feminist psychology and feminist therapy implication, what are the goals of feminist therapy? These are some questions we try to answer in this article. Feminist psychologists more than any other theorists, examine not only the psychological factors that lead to individuals' problems but also sociological influences like development (Sharf, 2004, pg. 437). Significance of this article lies in delineating and emphasizing implication of feminist psychology and therapy. The scope of this paper is organized in such a way that it starts with a short survey of feminism, feminist psychology emergence and development followed by feminist therapy, it's goals and techniques illustrated by a specific case study. Literature review was main methodology used in writing this article and case study as illustration of feminist therapy goals application and impact in practice.

\section{Origin and Developments of Feminist Psychology}

The term feminism or feminists first appeared in France and Netherlands in 1872 (Offen, 1987) and migrated to Great Britain in 1890 and to USA in 1910 (Cott, 1987). As Fredman states, the term combined the French word for woman, femme and isme, which referred to a social movement or political ideology (like socialism, communism). Feminisme 
connoted that women's issues belonged to the vanguard of change. Feminism as such had three distinctive phases. In the 1800's, the first wave activism was simply characterized as the women movement. After the 1910, it claimed political identity and during tumultuous 1960's as women's liberations advocating women's equality with men in work and politics. Within a decade, the older term feminism/feminist begun to be used to refer to the politics of this new movement (2002 ps. 3-5). Thus, as Freedman cites feminism is a belief that women and men are inherently of equal worth. Because most societies privilege men as a group, social movements are necessary to achieve equality between women and men with the understanding that gender always intersects with other social hierarchies (pg. 7). Hitchcock cites Karen Horney who in her essay to The flight from womanhood in 1922 said "female psychology has been constructed thus far "under the spell" of a male point of view, and "if we try to free our minds from this masculine mode of thought, nearly all the problems of feminine psychology take on a different appearance" (ps. 3536 2005). Thus, we can say that the term feminist psychology was originally coined by Karen Horney, a neo-Freudian psychoanalyst who founded psychology focused on gender and discovering how gender affects individual and wrote numerous articles in relation to women and their experiences. Feminist psychology embraces eight tenets such as inclusiveness, equality, seeking new knowledge, attending the context, acknowledging values, advocating change, attending to process, expanding psychological practice (Worell and Remer, 2002 ps. 16-17).

Psychology as a scientific field, just like almost all the other fields, was for decades dominated by male theory, research and practice. As a reaction to this domination women's movement emerged during the late 1960's and later made emphasis on feminist psychology. Therefore, feminist psychology originated as a criticism against the traditional assumptions of male dominated theory, research and practices, especially according to psychoanalytic theory. Feminist psychologists argued that Freud's theories, such as "penis envy" and hysteria, were gender biased. Besides, as Chenoweth argues, "the traditional Freudian psychoanalytic model is predicated on the male Oedipal conflict as the basis for normal psychosexual development and female sexuality is presented from the 
perspective of biological deficit based on the female gender position as castrated male" (Kaslow and Magnavita 2002, pg. 366). These Freudian concepts were particularly distasteful to supporters of the feminist movement and some strongly reacted and opposed them. Next to reactions to Freudian concepts, feminist developmental theorists pointed out that "Piaget, Erikson and Kohlberg all based their research on male norms and behavior" (Nugent and Jones, 2009, pg. 75).

Upon this opposition, Anna Freud, Margaret Mahler, and Karen Horney were among the first who broke of from the dominant psychoanalytic male views of human development. They offered compelling alternative arguments for concepts such as penis envy, female masochism, and feminine inferiority (Sommers-Flanagan \& SommersFlanagan, 2004, pg. 335). Among others who significantly contributed to the feminist psychology were Clara Thompson who wrote a book Interpersonal Psychoanalysis and Helene Deutsch who wrote a book Psychology of Women. From the above alternative arguments and concepts the feminist psychology was coined. Furthermore, feminist psychology was reaffirmed by Jean Baker Miller (1927-2006), with her books Psychoanalysis and Women (1973), and Toward a New Psychology of Women (1976), Phyllis Chesler who wrote Women and Madness (1972), and Juliet Mitchell who wrote Women: The Longest Revolution. They became known as feminist psychologists.

Feminist Psychology propagators were aware of the pressures of patriarchy, sexism and male chauvinism within therapy and counseling. Women naturally and personally discovered and felt that they were put down in a number of subtle ways, and that all sorts of expectations about the female role (assumed role) and how it should be played were built into the therapy process. They argued that assumed female roles actually hindered female patients and this is negatively reflected on their mental health. This was affirmed by Sommers and Flanagan who claimed that the "feminist theory in general and feminist theories in mental health particularly, has sought to identify and address forces and practices that are inherently psychologically damaging to women" (pg. 336).

Feminist psychologist based their reactions on the traditionally accepted psychological theories and practices regarding mental health 
standards based on gender that were harmful to women. Accordingly women were labeled of as mentally ill for political reasons (punishing women for not adhering to expected roles) and women tended to be diagnosed as "mentally ill" when they didn't conform to male stereotypes and protested the sexism of psychotherapy and psychotherapists. The womanless state of psychology and its development also contributed towards the emergence of feminist psychology. For example, Mary Whiton Calkins in 1891 establishes a psychology laboratory at Wellesley College, 1891. Calkins and Ladd Franklin were first female members of the American Psychological Association, and 1894 Margaret Floy Washburn becomes the first woman to be officially awarded the $\mathrm{PhD}$ degree in psychology, at Cornell University under E.B. Titchener, but their work was not recognized for a long time. Finally, the desire to report women's experiences from a woman's perspective was additional reason for the emergence of feminist psychology.

Even though feminist psychologists made significant developments in the field by writing numerous books, yet only by the beginning of the late 1970's they began developing feminist psychology theories. Therefore, Sommers-Flanagan (2004) outlined three distinct phases of theoretical development of feminist psychology. The first phase was characterized by borrowing therapeutic techniques that fit into the feminist philosophy, with the goal to empower all women by strengthening individual women. The second phase is marked by the inclusion of feminism into more psychological theories where feminists attempted to keep the parts of psychological theories that were sensible and that worked, but tried to eliminate the sexist elements that were present. The ongoing phase consists of trying to develop a complete theory that explains the common experiences of women and their difficulties arising from living in a society where they are devalued (Sommers and Flanagan, 2004)

\section{Feminist Therapy}

Once feminist psychologists developed the literature and theories they developed the criteria for successful therapists. Accordingly, feminist psychologists argue that, in order to be a successful feminist 
therapist a therapist should: examine sociological and psychological factors, help people understand the impact of gender roles and power differences in society; and differentiate sex and gender whereas sex is related to biological difference and gender is related to socially determined thoughts, beliefs and attitudes about men and women (Sharf, 2004, pg. 437).

In addition to feminist arguments, views and reaction to "male dominant scrutiny" feminist psychologists developed psychotherapy principles and offered entirely new concepts. In relation to the principles in therapy and counseling, after close revision, feminists contributed to the therapy field with following ideas: the personal is political (Social change needed), the counseling relationship is egalitarian (equality of relationship between a client and therapist), women's experiences are honored (not dismissed and discarded as of lesser value), definitions of distress and "mental illness" are reformulated, and there is an integrated analysis of oppression (Sommers and Flanagan, 2004, pg. 342).

In addition to therapy and counseling principles, feminists contributed new concepts. These concepts are emphasizing the client's role and expertise that encourage social action, wider sociopolitical and cultural context within which problems are viewed and challenge to traditional ways of psychological health assessment assuming that individual change best occurs through social change (Sharf, 2004, pg. 449). Hence, from feminist perspective, a successful therapist should be sensitive to these concepts as this was not always the case with traditional male therapists. According to feminist psychology, traditional male therapists work was colored by theories of personality (Sharf, $2004 \mathrm{pg}$. 439). This led to feminists to argue for the revision of personality theories. For example, Carol Gilligan and J. B. Miller take different approaches in describing the development of women's personality and the role of relationship in this development (Sharf, 2004, pg. 441).

In relation to the filed of personality theory, feminist psychologists start of by offering definite gender construction. This view reflects the work of Rachel Hare-Mustin and Jean Maracek (Worell and Remer, 2002, pp 14-15) who talk about two biases in the approach to gender. Alpha bias which relates to separating men and women into two 
categories and danger is in treating women as different and therefore inferior. And, beta bias which is treating women and men as identical and ignoring real differences. Therefore, constructions of gender contain two competing biases: alpha bias, which is the tendency to exaggerate malefemale differences; and beta bias, which is the tendency to minimize or ignore differences. Both biases have disadvantaged women in the work place. A presumption of female-male personality traits provides a rationalization for restricting women's work roles. However, arguing that gender differences are trivial one ignores real differences in women's and men's access to power and resources. An alternative approach to gender is suggested whereby attention is focused on the context in which behaviors are observed. Rather than viewing gender as an issue of absolute difference, gender should be viewed as a process rooted in an asymmetric power distribution between women and men. Otherwise, these issues will remain and they will negatively reflect the practice. Furthermore, as feminists argue, all these issues which need to be constructed are deeply rooted in all stages of human development. Thus, feminist psychologists react to developmental issues in childhood, adolescence and midlife issues with contribution of specifics in each.

As feminists argue, early childhood experiences and male emphasis contribute to development of an individual. For instance, early childhood practices such as preference for baby boys over girl babies and pressure to learn gender stereotypes significantly contribute to negative personality development. Furthermore, during the adolescence other specifics emerge, such as: development of secondary sex characteristics that can be very difficult for girls, breast development, focus on thinness, females valued for appearance rather than achievement, teen pregnancy issues, encouragement of independence in boys and nurturance and helplessness in girls. Feminists also consider midlife issues like menopause, devaluation of older women, violence, rape, incest, domestic abuse and child abuse. These issues are very important and sensitive and need to be addressed and objectively approached (Sharf, 2004, pg. 443). 


\section{Feminist Philosophical Approaches and Therapy Goals}

Given the gender construction and developmental specifics, feminist psychologist proposed particular therapy goals. The goals of feminist therapy are: to become aware of one's gender-role socialization process, to identify internalized gender-role messages and replace them with functional beliefs, to acquire skills to bring about change in the environment, to become personally empowered, symptom removal, selfesteem improvement/development, focusing on quality of interpersonal relationships (Sharf, 2004 pg. 451). These psychotherapy goals were applied in the case study which shortly follows. This case study points to positive outcomes of feminist therapy goals. Besides, therapy goals are based on four feminist philosophical approaches such as liberal feminism, cultural feminism, radical feminism and social feminism (women of color and lesbians) (Worell and Remer, 2002).

Liberal feminism focuses on helping women to overcome the constraints of their socialization patterns through personal empowerment of individual women, dignity, self-fulfillment and equality. This could be achieved by using specific intervention techniques accordingly, such as gender-role analysis and intervention, helping clients understand the impact of gender-role expectations in their lives, providing clients with insight into the ways social issues affect their problems, power analysis and power intervention, emphasizing the power differences between men and women in society, helping clients recognize different kinds of power they possess and how they and others exercise power and biblio-therapy (Sharf, 2004 pg. 440).

Cultural feminism is a philosophical approach which mainly focuses on oppression. According to this view, oppression stems from society's devaluation of women's strengths because it emphasizes gender differences. Hence, cultural feminism believes the solution to oppression lies in feminization of the culture so that society becomes more nurturing, cooperative and relational. Major goal of this approach is the infusion of society with values based on cooperation. Influenced by this approach, feminists argue that this can also be done by using specific techniques like: helping equalize the therapeutic relationship and provide modeling 
for the client, and thorough discussion of values, beliefs about society, and therapeutic interventions (Worell \& Remer 2002).

Third philosophical approach known as radical feminism focuses on the oppression of women, being embedded in patriarchy and changing social issues. Radical feminism seeks to change society through activism while therapy is viewed as a political enterprise with the goal of transformation of society. In order to attain this, radical feminists offer specific therapy intervention techniques such as assertiveness training, helping women to become aware of their interpersonal rights which transcend stereotypical sex roles, changing negative belief, implementing changes in their daily lives and reframing (Sharf, 2004 pg. 440).

The social feminism focuses on society and societal change in particular. An emphasis is placed on multiple oppressions and a belief that solutions to society's problems must include consideration of class, race and other forms of discrimination. Major goal of social feminism is to transform social relationships and institutions. Once gain, feminists preferring this approach offer specific therapy intervention techniques such as relabeling, changing the label or evaluation applied to the client's behavioral characteristics and re-focusing (Sharf, 2004 pg. 450 and 466). Based on the thorough and long work in the field of therapy, particularly working with women with mental health problems, feminist psychologists argue that three themes often come up in therapy such as anger, self-nurturance and autonomy. Feminist psychologist state that emergence of these three concepts in psychotherapy emerged due to women's frequent turning their anger inwards. Thus, they often need a good deal of encouragement to direct anger where it really belongs. Also, women are taught to nurture others and as a result develop huge sense of responsibility but may not be good at nurturing themselves. And in turn, as Gilligan states, responsibility becomes, in its conventional interpretation, confused with a responsiveness to others that impedes a recognition of self (pg. 127). Finally women are taught cooperation and find networking very easy, but may need a lot of help to see out through their own eyes and ask "what do I need myself"? This question tends to arise much anxiety and even guilt, and a feminist approach is necessary if women are to feel that these reactions are unnecessary (Gilligan, 1982). - 
Therefore, as Sharf argues, feminist therapy is characterized by specific techniques such as gender role analysis, gender role intervention, power intervention, assertiveness training, reframing and relabeling and demystifying (ps. 451-456). These techniques are aimed toward increasing self-awareness, acceptance of self-awareness, strengthening of self-acceptance, developing the power to act, recognizing societal restraints, accepting or combating societal restraints, acceptance of self and other women.

Feminist psychologists also contributed to the therapy of trauma survivors. The work of L. Walker and M. Greenspan is very significant. They proposed the guiding principles of feminist therapy, indicating that there are six tenets of feminist-therapy theory (Cantor, 1990, pp. 78-79). Firstly egalitarian relationships between clients and therapists serve as a model for women to take personal responsibility to develop egalitarian relationships with others instead of the more traditional passive, dependent female role. While it is accepted that the therapist knows more in terms of psychology, the client knows herself better. That knowledge is as critical as the therapist's skills in developing a successful therapeutic relationship. Then, power - women are taught to gain and use power in relationships, and the possible consequences of their actions. Subsequently, enhancement of women's strengths so much of traditional therapy focused on a woman's shortcomings and weaknesses that feminist therapists teach women to look for their own strengths and use them effectively. Therefore, the feminist therapist focuses on the enhancement of women's strengths rather than remediation of their weaknesses and non-pathology-oriented and non-victim blaming framework that perceives women's problems as coping mechanisms within social context. Finally, throughout the education women are taught to recognize their cognitions that are detrimental, and encouraged to educate themselves as to the plight of all women. They are also more self-disclosing than other therapists thus removing we versus they barrier between therapists and their clients. This limited reciprocity is a feminist goal that is believed to enhance the relationship.

Secondly, in her book "A New Approach to Women and Therapy" (1983), Miriam Greenspan explores the impact of "traditional" 
and "growth" therapies on women. Furthermore a book also describes "feminist" therapy in action by listing or naming therapist's tasks such as realization that the therapist's most essential tool is herself as a person and an attempt to demystify a sense of their own power in therapy. As Greenspan argues, therapy must be geared towards helping the client to realize his/her own rescuing mission. Such rescue power is indeed very often derived from within. In this regard, rules of the therapeutic relationship should be overtly stated and mutually agreed upon. While the client and therapist explore their expectations of one another both together come to an agreement with regards to mutual rights and responsibilities.

Throughout the world women have marginalized and neglected many rights. Women's activism had begun in the late eighteen century as their reaction to unjust position in societies in a form of various women movements what is known as feminism nowadays. A Worell and Remer argue, the range of definitions and theories about feminism leads us to conclude that feminism, as a social and political movement, is broad and multifaceted. It is clear that many differing attitudes and values are associated with being a feminist, but all roads lead to a simple conclusion: Equality of opportunity, respect, and fair treatment for all persons is essential (pg. 17). Thus, feminist principles can be applied to all professional activities. For example, feminists in psychology propose not only eight tenants in general but also contributed to the field of theory as well as practice. Feminist therapy offers significant principles and goals with solemn practical implications on individual and societal level such as, symptom removal, self esteem, quality of interpersonal relationships, body image and sensuality, attention to diversity and political awareness and social actions (Sharf, 449-450).

Self-esteem is integrated part of self confidence and self respect and a very important concept in feminist therapy. William James first introduced the self-esteem topic more than a century ago stating "self-feeling in this world depends entirely on what we back ourselves to be and do. It is determined by the ratio of our actualities to our supposed potentialities; a fraction of which our pretensions are the denominator and the numerator our success: thus, such a fraction may be 
increased as well by diminishing the denominator as by increasing the numerator (Mruk, 2006 pg. 12). Morris Rosenberg (1965) offered the other definition and defines self esteem as a positive or negative attitude toward a particular object, namely, the self. Thus, high self-esteem, in Rosenberg's scale expresses the feeling that one is "good enough." The individual simply feels that he is a person of worth; he respects himself for what he is, but he does not stand in awe of himself nor does he expect others to stand in awe of him. He does not necessarily consider himself superior to others (Mruk, 2006 pg. 16). On the other hand, Nathaniel Branden offered another definition in1969 when he said that Self-esteem has two interrelated aspects: it entails a sense of personal efficacy and a sense of personal worth. It is the integrated sum of self confidence and self-respect. It is the conviction that one is competent to live and worthy of living. (Mruk, 2006 pg. 19).

As the aforementioned definitions of self-esteem indicate self esteem contains two dimensions, worthiness and competence. For example, as Mruk sates, White talked about "love-worthiness" and identification with parental figures or objects while Coopersmith connected worthiness to various patterns of parenting. Then, Rosenberg spoke of "reflected appraisals," and humanists like Rogers focused on being accepted "unconditionally" as having a major impact on our worthiness. In a certain sense, then, the first source of worthiness we encounter, and perhaps also the first source of self-esteem, is being valued by others. Also, later on in life it is important to accept ourselves to achieve authentic self-esteem, but even that task is made easier if we have had what Winnicot called "good enough" acceptance in the first place (pg. 170).

Self esteem in feminist therapy requires a move away from being dependent on external sources of self esteem (what others think) to the self esteem based on one's own feelings about oneself (pg. 449). Both gender-role and feminist analysis help clients reframe problems and develop new lenses for understanding issues, which often lead to renewed self-esteem. This could be achieved by feminist therapy techniques as the case which follows shows. 


\section{A Case Study: Self-Esteem}

Since the time they are born women have been encouraged to limit their personal development. At the same time they have been encouraged to seek a male to provide income and identity and see themselves as adjunct to male needs, careers, and achievements instead. Many women seek counseling and support when the marriage explodes, when they are not able to realize self potentials due to the lack of self esteem, when the "they lived happily ever after story goes bad, or, for whatever reasons, they've outgrow their worlds and don't know what's making life seem so meaningless. Feminist therapists are alert for signs of these gender-role constraints and developmental arrests. Following is a case illustration of a woman who turned to Counseling center CEI Nahla who reported lack of self esteem which prevented her personal growth. Based on the specific issues she raised in therapy, the therapist (the author of this article) applied feminist therapy goals to help her express and assert self in order to develop self esteem based on her own feelings. Six therapy sessions were conducted.

Female, 35 year old, employed, married with one child, sought therapy due to the lack of self confidence and self esteem especially from public speaking. She reported that when addressing colleagues and coworkers she experienced face redness, extreme sweating, body temperature rise, heart pounding and stuttering. These symptoms also led to her to avoid such situations, keeping quiet during meetings and, making excuses or pretending of not feeling well. Accordingly, she felt regularly ashamed and very embarrassed, especially due to face redness, because she "wondered about male colleagues reactions." On the other hand, she was capable hard working employee who made quite many contributions to the company. Yet, she wondered why she has low self esteem and self confidence despite significant results?

During therapy, many issues came out as sensitive and important to this client. She grew up in a religious family as a second child, together with two brothers. The oldest brother was always preferred by her parents and always put as an example for everything. Although she faired of pretty well having good paid job, independent family life, knowledge of one foreign language and lots of skills that prove her 
excellence her brother still received greater attention from the family. In addition, she recalled situations from her early childhood when she was "imitating others" and "acting as others" all for the sake of acceptance and recognition. She also recalled sarcastic remarks towards her parents and brother and later to anyone when she experienced injustice and rejection." During the therapy she realized that this was indeed her cry for an attention and recognition and her whole life was revolving around trying to come into the picture of equal worth and acceptance as her brother. She did her best trying to get her parents attentions thus she made it her duty to become: "very good daughter (she was sick frequently but still managed to care for her self and her family), an excellent cook and housewife plus great worker/professional." Still, despite all this, this was not enough for her inner peace and satisfaction. Therapy process clearly pointed client's gender role analysis and socialization process and issues and necessity of applying feminist therapy goals.

Therapy goals were firstly directed to client's awareness of her gender-role socialization process. We tackled this concern and the client became aware of presupposed subjectively structured female and male rights and positions within the society. Then, religious reasons were also pointed out as they frequently affect women's self-esteem. As a result, client's personal attitudes such as "I am not worth and I am not good because I am a female" very negatively reflected on herself-esteem and self-worth. Throughout the therapy she realized that "her efforts and fights for others, others rights, her sensitivity to others" "her acting and imitating" was related to her reaction to her parents preference of her brother over her and clear wish to be acknowledged and recognized by them. Then, she realized due to her powerless position as a women she expressed injustice and rejection by using sarcasm. Her inner wish was always directed to "love me and accept me, I am good person even though I am female." When she became aware of this her personal awareness eased the symptoms of extreme self consciousness, redness and body temperature, heart pounding and stuttering. Her self esteem improved as well. 
This case study also examines the second feminist therapy goal in order to identify internalized gender-role messages and replace them with functional beliefs. As a result of her parents' preference for her brother, client's internalized gender role message was "I am worthless because I am female." An attempt was made to replace this dysfunctional belief with "even though my parents prefer my brother because he is male, they still love me and they show me this through many small signals.

In relation to the third goal in feminist therapy client's success made changes in regards to recognition and appreciation of inner self. She began ceasing to devalue her inner self in association to the family and social relations. In addition, she also found her unique position within her religion and religious community. Such changes of self perceptions led to her realization of male bias and the proper positioning the relation to self, family, society and religion.

She became aware of her anger towards her parents and her feeling of betrayal. She managed to forgive them by turning her anger into thinking "this is the best they could do and offer to me" but I am aware of these issues now and I won't repeat their mistakes." She is able to normally communicate her negative emotions and dissatisfaction to her parents when she notices their "male" preference without using sarcasm anymore. Our sessions closed with her expression "I feel powerful and more confident now and I am able to link my behavior to my inner feelings and I am able to replace these behaviors with my real needs and communicate them."

This case study illustrates impact of social context or gender role on individual development and its effect on women's self esteem. Application of feminist therapy goals and principles shows positive psychotherapeutic outcomes in this case. It also demonstrates and affirms implication of feminist theory and practice. 


\section{Conclusion}

Work of feminists in general is immense and they contributed ample to many fields and Psychology is one of them. Contribution of feminists to the field of psychology can be noticed through their input into the theory as well as practice but they also tackled the filed of personality and some specific developmental stage. In essence, feminist therapy was highly influenced by four feminist philosophical approaches such as liberal feminism, cultural feminism, radical feminism and social feminism. These feminist philosophical approaches focus on helping individual women to overcome the limits and constraints of their socialization patterns through personal empowerment of individual women, dignity, self-fulfillment and equality, more effective therapy outcomes, infusion of society with values based on cooperation oppression to overcome oppression, changing society through activism and transforming social relationships and institutions, respectively. In the field of mental health, the consideration of sex, gender, and cultural diversity in the prevalence, etiology, diagnosis, and treatment of a range of human problems was conspicuously absent until recently (Worell \& Remer, 2002). Absence of these important issues stipulated an intervention. Feminists propose public action and a social change because, as Worell and Remer argue, it is insufficient to "fix" the woman for functioning in a dysfunctional society (2002). We can reiterate with Worell's and Remer's citation

A feminist lens encourages us to look at the uses of power and how status hierarchies deprive women from all social locations of their respect, freedom, and equality. In valuing women's experiences, we legitimize the study of women in all their diversities as an important scientific enterprise, and we encourage innovative methods of research to explore these experiences. We reject the notion of totally objective science or practice related to behavior and call on educators, researchers, and practitioners to acknowledge their values and biases (pg.18). 
Further research and more critical approach are also recommended with likely different conclusions on this topic.

\section{References}

Burman, E. (1997). Deconstructing feminist psychology. New York: Sage.

Burr, V. (1998). Gender and social psychology. New York: Routledge.

Cott, Nancy F. (1987). The grounding of modern feminism. New Haven: Yale University Press.

Freedman, E. B. (2002). No turning back: The history of feminism and the future of women. New York: Random House Publishing.

Funkerburk, J. R., \& Fukuyama, M. A. (2001). Feminism, multiculturalism and spirituality: Convergent and divergent forces in psychotherapy. Women and Therapy, 24 (3/4)1-18.

Gilligan C. (1982). In a different voice. Psychological theory and women's development. Cambridge. Massachusetts: Harvard University Press.

Greenspan, M. (1983). A new approach to women and therapy. New York: McGraw-Hill.

Hitchcock S. T. (2005). Karen Horney pioneer in feminine psychology. Philadelphia: Chelsea House Publishing.

Kaslow F. W and Magnavita J.J.(2002). Comprehensive handbook of Psychotherapy, vol. 1. New York: Wiley and Sons Inc.

Mruk C. J. (2006), Self-esteem, research, theory and practice. Toward a positive psychology of self-esteem, $3^{\text {rd }}$ edition, New York: Springer Publishing Company.

Nugent, F. A., Jones K. D., (2009) Introduction to the profession of counseling; $5^{\text {th }}$ ed., New Jersey: Pearson Education. Inc.

Offen, K., (1987) "Les origines des mots 'feminisme' et 'feministe'." Revue d'histoire moderne et contemporaire. July-September 34: 492-496

Sharf S. R., (2004): Theories of psychotherapy and counseling: Concepts and cases, $3^{\text {rd }}$ ed. Pacific Grove: CA, Brooks/Cole 
Sommers-Flanagan J. \& Sommers-Flanagan R. (2004). Counseling and psychotherapy theories in context and practice, skills, strategies and techniques, New Jersey: Wiley and Sons Inc.

Unger, R. K. (2001). Handbook of the psychology of women and gender (3rd ed.). New York: Wiley and Sons Inc.

Walker, Lenore E.A.(1990). A feminist therapist views the case. In Dorthy W. Cantor (Ed.), Women as Therapists. New York: Spring Publishing Company.

Worell, J. \& Remer, P., (2002). Feminist perspectives in therapy: Empowering diverse women._ $2^{\text {nd }}$ Ed. New Jersey: Wiley and Sons Inc. 